\title{
Tratamiento de lesiones del cartílago articular con terapia celular
}

\author{
Treatment of joint cartilage lesions with cell therapy
}

\author{
Isaac Manuel Fuentes-Boquete ${ }^{\mathrm{a}, \mathrm{b}}$ María del Carmen Arufe Gonda ${ }^{\mathrm{a}, \mathrm{b}}$ Silvia María \\ Díaz Prado ${ }^{\mathrm{a}, \mathrm{b}}$ Tamara Hermida Gómez ${ }^{\mathrm{b}}$ Francisco Javier de Toro Santos ${ }^{\mathrm{a}, \mathrm{b}}$ \\ Francisco Javier Blanco García ${ }^{\text {b,c }}$
}

\author{
${ }^{a}$ Departamento de Medicina. Universidade da Coruña. A Coruña. España \\ ${ }^{b}$ Laboratorio de Investigación osteoarticular y del envejecimiento. Centro de Investigación Biomédica. CHU \\ Juan Canalejo. A Coruña. España \\ ${ }^{c}$ Cátedra Bioibérica de Terapia Celular. Universidade da Coruña. A Coruña. España
}

\begin{abstract}
Resumen
Las lesiones del cartílago articular que no afectan a la integridad del hueso subcondral no se reparan espontáneamente. El carácter asintomático de estas lesiones propicia la progresiva degeneración articular y el desarrollo de un proceso artrósico. Para evitar la necesidad de reemplazo protésico, se han desarrollado distintos tratamientos celulares con el objetivo de fomar un tejido de reparación con estructura, composición bioquímica y comportamiento funcional iguales que los del cartílago articular natural. Las técnicas basadas en facilitar el acceso al sistema vascular generan un tejido de reparación fibrocartilaginoso que no reúne las condiciones del cartílago articular. El implante de condrocitos autólogos y la mosaicoplastia autóloga aportan un tejido de reparación de mayor calidad, pero ambas técnicas implican la escisión de cartílago sano, bien para obtener una elevada cantidad de condrocitos, bien para extraer cilindros osteocondrales que se implantan en el defecto. Las células madre mesenquimales constituyen una prometedora herramienta de reparación del cartílago articular en fase de experimentación. Aunque las estrategias actuales de terapia celular producen mejorías clínicas y funcionales, todavía no es posible generar un tejido de reparación resistente a la degeneración y con características de cartílago articular normal.
\end{abstract}

\begin{abstract}
Articular cartilage lesions which do not affect the integrity of subchondral bone, they are not able to repair it expontaneously. The asymptomatic nature of these lesions induces articular cartilage degeneration and development of an arthrosic process. To avoid the necessity to receive joint replacement surgery, it has been developed different treatments of cellular therapy which are focused to create new tissues whose structure, biochemistry composition and function will be the same than native articular cartilage.

Approaches used to access the stream produce a fibrocartilaginose tissue which is not an articular cartilage. Implantation of autologous chondrocytes and autologous mosaicplasties induces a quality better articular cartilage. Furthermore both techniques involve damage in the sane cartilage; because of trying to get a big amount of chondrocytes or because of extraction osteochondral cylinder which will be implanted in the injured joint. The stem cells are a promising toll to repair articular cartilage, however they are in a previous experimentation step yet. Although the present studies using cellular therapy improves clinically and functionally, it is not able to regenerate an articular cartilage which offer resistance the degeneration process.
\end{abstract}

Palabras clave

Cartílago articular; Terapia celular; Lesiones focales de cartílago; Artrosis; Condrocito; Célula madre

Key words

Articrapy cartilage; Cell therapy; Focal cartilage lesions; Osteoarthritis; Chondrocyte; Stem cell 


\section{Introducción}

El implante de células con capacidad condrogénica o el acceso a la médula ósea son modalidades de terapia celular para reparar lesiones del cartílago articular. El objetivo final no es sólo "cicatrizar" el defecto condral (reparación), sino generar un tejido de nueva formación con una estructura, una composición bioquímica y un comportamiento funcional iguales a los del cartílago articular nativo (regeneración). Esta revisión aborda diferentes opciones de terapia celular del cartílago articular desde una perspectiva clínica y experimental.

\section{Penetración del hueso subcondral}

Cuando la lesión afecta al cartílago y el hueso subcondral (lesión osteocondral), se produce la migración de células mesenquimales de la estroma de la médula ósea, que protagonizan la reparación del defecto ${ }^{1}$. Esta reparación está limitada por el tamaño del defecto, de modo que la capacidad de reparación espontánea en lesiones osteocondrales de gran tamaño es prácticamente nula. La abertura del área vascular subcondral se lleva a cabo mediante distintas técnicas quirúrgicas, como la abrasión artroscópica ${ }^{2}$, las perforaciones del hueso subcondral $^{3}$, la espongialización ${ }^{4}$ y la microfractura ${ }^{5}$, que es la que ofrece mejores resultados.

Estudios experimentales en conejo ${ }^{6,7}$ y perro ${ }^{8}$ han observado que el tejido de reparación así formado es de tipo fibrocartilaginoso (diferente del cartílago hialino articular en composición, organización estructural y propiedades mecánicas) y muestra con el tiempo signos de degeneración ${ }^{1,7}$. No obstante, los resultados clínicos parecen contradecir esta calidad del tejido de reparación. El tratamiento por microfractura de defectos osteocondrales de rodilla ha aportado a los 2 años unos buenos resultados clínicos ${ }^{9}$, que parecen depender de la edad y muestran más efectividad en pacientes menores de 40 años ${ }^{10}$. Aunque se ha indicado que un proceso de degeneración del tejido de reparación se inicia a los 18 meses de la microfractura ${ }^{11}$, se ha descrito a largo plazo (7-17 años) el mantenimiento de la mejoría funcional y la disminución del dolor ${ }^{12}$.

\section{Injertos de periostio y pericondrio}

Estas membranas contienen células madre mesenquimales que pueden experimentar condrogénesis $^{13,14}$. El implante de periostio o de pericondrio forma un tejido de reparación fibrocartilaginoso que parece no madurar con el tiempo ${ }^{15,16}$. No obstante, los efectos clínicos del implante de pericondrio parecen ser similares a los de la perforación subcondral, pues a los 10 años de aplicar ambos procedimientos no se observaron diferencias significativas entre sus resultados ${ }^{17}$.

\section{Injertos osteoperiósticos}

El injerto de cilindros de hueso recubiertos de periostio produce en modelos animales un tejido neoformado fibroso ${ }^{18}$ que, con inductores condrogénicos, llega a adquirir un aspecto fibrocartilaginoso $^{19}$. Probablemente, el sangrado de médula ósea en la lesión interfiere con la acción reparadora de la capa germinal del periostio. De hecho, en el conejo, cerca del $67 \%$ de las células del tejido de reparación tras el injerto osteoperióstico procedían de la médula ósea ${ }^{20}$. En contradicción con esta discreta calidad histológica del tejido de reparación, se ha descrito que este procedimiento aporta mejoría de la función articular y alivio del dolor ${ }^{21}$.

\section{Mosaicoplastia}

Se considera que este procedimiento es una prometedora alternativa para el tratamiento de defectos condrales y osteocondrales de pequeño y mediano tamaño ${ }^{22}$. Básicamente, consiste en la translocación al defecto articular de cilindros osteocondrales obtenidos de zonas poco comprometidas con la absorción de carga (fig. 1). La zona donante se autorrepara con células mesenquimales del estroma de la médula ósea que promueven un tejido fibrocartilaginoso. Con el seguimiento artroscópico hasta los $5^{23}$ y los 10 años ${ }^{24}$ del implante, se ha observado supervivencia 
del cartílago hialino trasplantado, congruencia de las superficies articulares y reparación fiborcartilaginosa de las zonas donantes. No obstante, si los cilindros osteocondrales sobresalen de la superficie, producen problemas articulares. Así, pacientes con este problema manifestaron a los 4 meses de la mosaicoplastia sensación de pinzamiento e incluso dolor. Su valoración artroscópica reveló fisuras en los cilindros osteocondrales y fibrillas en la superficie articular anexa ${ }^{25}$.

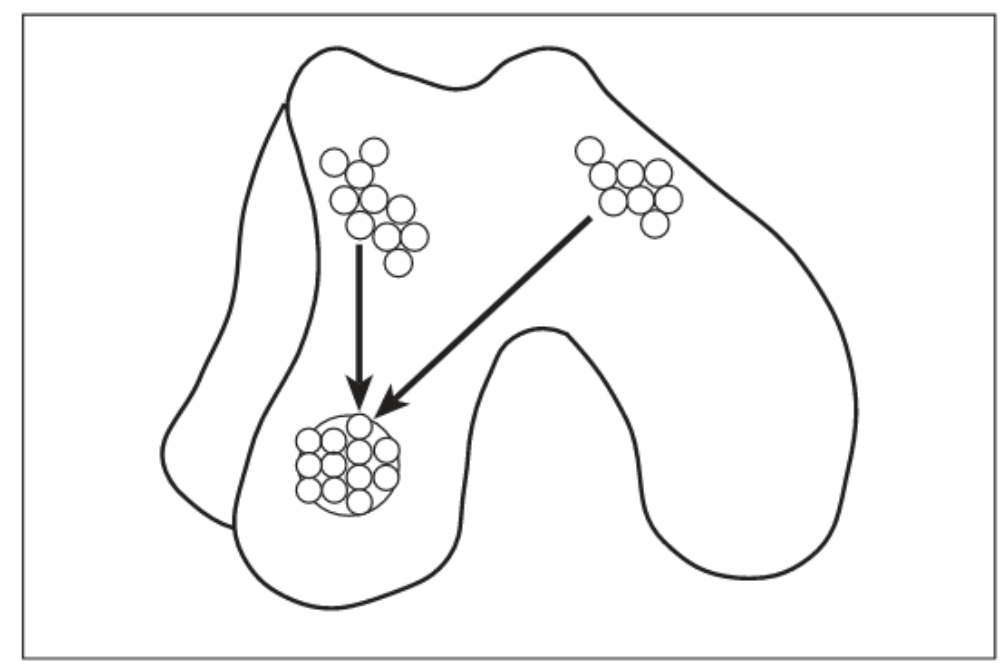

Figura 1. Mosaicoplastia. Los cilindros osteocondrales obtenidos de zonas poco comprometidas con la absorción de cargas se implantan en la zona de la lesión.

La mosaicoplastia autóloga está limitada por el tamaño del defecto, que determina el número de cilindros osteocondrales necesarios. Por otra parte, el tejido implantado procede de una zona de poca carga, con menor grosor y diferente estructura histológica. El alotrasplante puede dar solución a estas cuestiones: se evita la lesión en la zona de poca carga de cartílago, es posible obtener un número elevado de cilindros osteocondrales y éstos pueden proceder de la misma zona de carga. Además, los problemas inmunitarios son escasos debido al carácter avascular del cartílago y el encapsulamiento de los condrocitos en la matriz extracelular. De hecho, el alotrasplante osteocondral en rodilla está bien integrado y ofrece una consistente mejoría funcional y del dolor a los 2 años $^{26}$; después de 10 años la durabilidad es del $85 \%$ de los implantes ${ }^{27}$.

\section{Autotrasplante de condrocitos}

Actualmente, la alternativa terapéutica más eficaz para reparar lesiones focales del cartílago articular es el implante de condrocitos autólogos ${ }^{28-31}$. Este procedimiento también es aplicable a pacientes con osteocondritis disecante ${ }^{32}$, pero no a articulaciones artrósicas. El autotrasplante de condrocitos encuentra una limitación importante en la edad, y es recomendable utilizar esta técnica en pacientes menores de 55 años.

Este procedimiento consiste en obtener por artroscopia explantes de cartílago aticular de zonas poco comprometidas con la carga (fig. 2). Ya en el laboratorio, de los explantes se aíslan condrocitos, que proliferan in vitro hasta obtener un número apropiado para el implante (10-12 millones de células). En una segunda intervención quirúrgica, se cierra la cavidad del defecto con periostio del propio paciente y se inyectan los condrocitos. Este tratamiento presenta algunas limitaciones: a) la obtención de explantes supone una intervención quirúrgica adicional y un daño añadido al cartílago articular que puede originar un proceso artrósico; b) la proliferación in vitro de los condrocitos debe ser limitada, pues con las divisiones celulares disminuye su capacidad de producir cartílago estable in vivo ${ }^{33}$; c) con el envejecimiento disminuye la densidad celular del cartílago, la capacidad de proliferación in vitro de $\operatorname{los}_{\text {condrocitos }}{ }^{34}$ y el potencial condrogénico 
del periostio ${ }^{35}$, y d) el proceso de cultivo celular resulta demasiado largo (3-6 semanas) y no está exento del riesgo de contaminación.
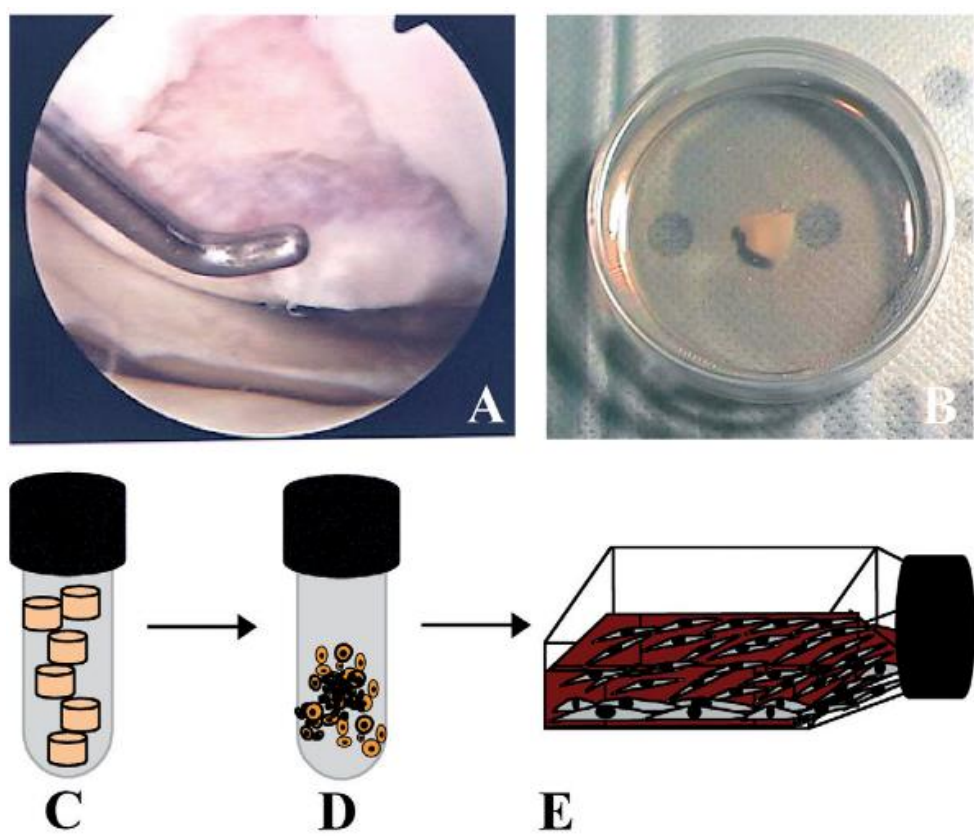

$\mathbf{E}$
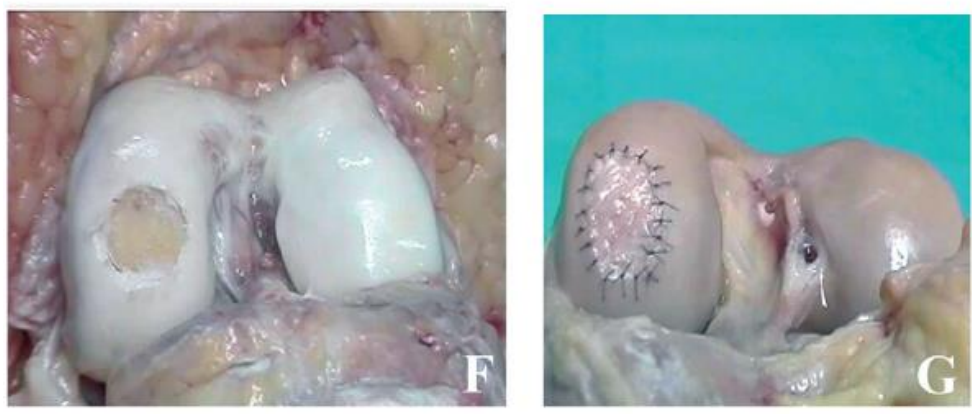

Figura 2. Autotrasplante de condrocitos. A y B: toma de biopsia. C y D: los condrocitos se obtienen triturando el cartílago y procediendo a su digestión enzimática (tripsina y colagenasa tipo IV). E: las células proliferan en un frasco de cultivo a $37^{\circ} \mathrm{C}$. F: cóndilo femoral con lesión condral. G: en la cavidad del defecto, cerrada con una membrana (periostio, colágeno tipo I/III), se inyecta la suspensión con condrocitos.

El primer artículo sobre el autotrasplante de condrocitos en pacientes data de $1994^{28}$. La valoración clínica y artroscópica a los 2 años del implante femoral aportaba buenos resultados. Trabajos posteriores han demostrado la durabilidad del implante, con buenos resultados clínicos después de 5-11 años del tratamiento ${ }^{32}$.

El análisis histológico de biopsias del tejido neoformado ha mostrado una cierta heterogeneidad en la calidad del tejido de reparación. De 41 biopsias tomadas tras 1 año del implante, un $10 \%$ consistía en cartílago hialino; un $24 \%$, una mezcla de cartílago hialino y fibrocartílago; un $61 \%$, fibrocartílago, y un $5 \%$, tejido fibroso ${ }^{36}$. Otros estudios han mostrado al año del implante la coexistencia en la misma biopsia de regiones con morfología fibrocartilaginosa y regiones con morfología hialina, ambas con proteoglucanos y colágeno tipo $\mathrm{II}^{29,31}$. Además, se observaba actividad de agrecanasa y metaloproteasas, con una mayor actividad de la agrecanasa en las regiones fibrocartilaginosas ${ }^{31}$, y la expresión en el ARNm de los procolágenos tipo IIA y tipo IIB $^{37}$, característicos respectivamente del estado precondrocítico y de condrocitos diferenciados ${ }^{38}$. Estos datos indican que el autoimplante de condrocitos es capaz de inducir la regeneración del cartílago articular, probablemente por el reemplazo y la remodelación de una matriz inicial fibrocartilaginosa, mediante degradación enzimática y síntesis de colágeno tipo II. Se considera 
que este proceso continúa más allá de los 24 meses después del implante ${ }^{30,39}$ y se desarrolla en tres etapas clave: proliferación celular (abarca las primeras 6 semanas), transición (entre las semanas 7 y 26) y remodelamiento (más allá de 27 semanas) ${ }^{40}$.

Se ha cuestionado el uso de la membrana de periostio para retener la suspensión de condrocitos, utilizando como argumentos la necesidad de realizar una extensa incisión quirúrgica, la hipertrofia periférica del implante de periostio y su potencial de calcificación ectópica. Como alternativa, se propone la utilización de una membrana de colágeno tipo I/III ${ }^{41-43}$. Un reciente estudio comparativo entre ambas técnicas no aportó diferencias significativas en cuanto a la valoración clínica, aunque el análisis artroscópico demostró un significativo número de pacientes que necesitaron "rasurado" de la hipertrofia periférica en el implante de periostio ${ }^{44}$.

Otras alternativas terapéuticas son el alotrasplante ${ }^{45-47}$ y el xenotrasplante de condrocitos ${ }^{48,49}$. El alotrasplante está condicionado por la necesidad de donantes y las limitaciones del almacenamiento de cartílago o de condrocitos, pues la criopreservación modifica la supervivencia y la proliferación de los condrocitos ${ }^{50}$. Respecto al xenotrasplante, apenas se ha investigado. Ambos procedimientos encuentran en la barrera inmunitaria una de sus principales objeciones. No obstante, si bien los condrocitos aislados resultan inmunógenos, el aloimplante de condrocitos atrapados en su matriz extracelular ${ }^{47}$ o embebidos en geles de colágeno o agarosa ${ }^{45,46}$ produce nulas o escasas reacciones de rechazo. Por otra parte, tras el xenotrasplante in vivo de condrocitos de cerdo en defectos condrales de conejo cerrados con membrana de periostio, no se observaron signos de infiltración de células inmunitarias ${ }^{49}$.

\section{Trasplante de células madre mesenquimales}

Las células madre mesenquimales (MSC) pueden diferenciarse in vitro en una gran variedad de tipos celulares, como adipocitos, condrocitos y osteoblastos ${ }^{51}$. Estas células se aíslan desde una pequeña muestra de tejido, proliferan en cultivo hasta obtener cantidades apropiadas para aplicaciones clínicas y pueden ser implantadas en el mismo paciente. Así, las MSC constituyen una herramienta potencial para reparar tejidos eludiendo problemas relacionados con el rechazo inmunitario del alotrasplante y el conflicto ético por usar células madre embrionarias.

Las MSC están ampliamente distribuidas in vivo, de modo que se puede aislarlas de médula ósea $^{52}$, periostio $^{53}$, pericondrio ${ }^{54}$, membrana sinovial ${ }^{55}$, tejido conectivo de la dermis y del músculo esquelético $^{56}$, grasa ${ }^{57}$, sangre del cordón umbilical ${ }^{58}$ y periférica $^{59,60}$, membrana amniótica ${ }^{61}$ e incluso del propio cartílago articular ${ }^{62}$. Aunque la médula ósea es la fuente tisular de MSC más utilizada, la sangre de cordón umbilical se está revelando como fuente de gran cantidad de células madre, susceptibles de diferenciación a cualquier tipo celular y con ventajas derivadas de su estado inmunitario y sus telómeros sin $\operatorname{acortar}^{63}$.

Actualmente, no hay marcadores específicos para la determinación precisa de MSC. Los principales criterios para su identificación son su adherencia al plástico del frasco de cultivo y su morfología fibroblástica ${ }^{64}$, su capacidad de proliferación prolongada en cultivo manteniendo sus características de células madre, su capacidad para diferenciarse in vitro en células de origen mesodérmico (condrocitos, adipocitos, osteoblastos) y su carencia de expresión de antígenos hematopoyéticos típicos como CD34 y CD45 ${ }^{65}$. Además, se ha relacionado diferentes marcadores de superficie con las MSC. Entre los más ampliamente utilizados están Stro-1, CD44, CD73, CD90, CD105 y CD166.

La escasa cantidad de MSC aisladas de una muestra de tejido hace necesaria su proliferación in vitro. Pero el número de divisiones mitóticas debe ser limitado, pues durante el cultivo in vitro las MSC envejecen y experimentan una marcada disminución de su capacidad proliferativa ${ }^{66,67}$ y una pérdida gradual del potencial de diferenciación múltiple ${ }^{66,68}$. El mantenimiento de fenotipo y capacidad de diferenciación es proporcional a la telomerización de los cromosomas ${ }^{69}$. Los telómeros se acortan en cada división celular, pero en las células madre embrionarias se restituyen por la acción de la enzima telomerasa. En las MSC, esta enzima muestra nula ${ }^{70}$ o baja actividad $^{68,71,72}$. La edad del paciente también influye en las características de las MSC, ya que con el envejecimiento se reduce su capacidad proliferativa ${ }^{73}$. 
Diversos estudios señalan que la población de MSC comprende subpoblaciones de células en diferentes estados de diferenciación y que la capacidad de diferenciación puede variar en función del tejido del que se las aísla. Así, las MSC procedentes de médula ósea muestran una mayor tendencia a la diferenciación osteogénica ${ }^{74}$, en tanto que las MSC de origen sinovial tienen mayor tendencia a la diferenciación condrogénica ${ }^{75}$.

En las mismas condiciones de cultivo y diferenciación, las MSC aisladas de membrana sinovial muestran más potencial condrogénico que las derivadas de médula ósea, periostio, músculo esquelético o tejido adiposo ${ }^{76}$. La reparación en modelos animales de lesiones condrales con MSC embebidas en gel de colágeno ${ }^{45}$ o inyectadas en los defectos cerrados con periostio ${ }^{77}$ indica que las MSC son capaces de diferenciarse de acuerdo con el medio biológico en el que se encuentran. Trabajos realizados por diferentes grupos intentando determinar si las MSC inyectadas intraarticularmente se movilizan hacia el cartílago dañado y reparan el defecto obtuvieron resultados opuestos. En rodilla de cabra, con artrosis inducida por rotura meniscal y resección del ligamento cruzado anterior, se observó tras 6 semanas de la inyección intraarticular de MSC reparación del menisco, pero no del cartílago ni del ligamento ${ }^{78}$, lo que evidencia la movilización de las células hacia el menisco, pero no hacia el cartílago. En cambio, la inyección intraarticular de MSC en rodilla de rata mostró que estas células se movilizaban hacia todos los tejidos afectados, incluido el cartílago, y contribuían a la regeneración tisular ${ }^{79,80}$. Son escasos los trabajos sobre MSC utilizados para tratar lesiones condrales humanas. En rodillas con osteoartritis, se implantaron MSC embebidas en gel de colágeno en defectos condrales cerrados con membrana de periostio; tras 42 semanas, se observaron mejores resultados artroscópicos e histológicos que en los pacientes osteoartríticos sin implante, aunque esta mejoría no resultó significativa en el aspecto clínico $^{81}$.

Todavía hay dudas sobre la utilización de MSC para tratar lesiones condrales, en gran medida porque no se conoce con suficiente detalle las etapas de diferenciación condrogénica de estas células y no se dispone de protocolos que garanticen la diferenciación hacia el fenotipo deseado. Así, la plasticidad de las células derivadas de MSC puede conducir a alteraciones no deseadas en el fenotipo ${ }^{82,83}$

\section{Terapia génica}

La introducción de productos génicos en el ámbito del daño tisular puede favorecer el proceso de restauración del cartílago articular. Este proceso implica determinar los genes y las células adecuadas para la transferencia génica (condrocitos, células condrogénicas y células de la membrana sinovial) usando diferentes vectores para incorporar los $\mathrm{ADNc}^{84}$. Distintos factores anabólicos (miembros de la superfamilia de TGF- $\beta$, IGF-1, FGF y HGF) pueden inducir condrogénesis y síntesis de los componentes de la membrana extracelular, en tanto que las moléculas antiinflamatorias (interleucina [IL] 4, IL-10, IL-1Ra, TNFsR) pueden actuar como inhibidores de la degradación del cartílago ${ }^{85}$.

La membrana sinovial resulta apropiada para terapias condroprotectoras ${ }^{86}$. La transfección viral in vivo del gen $I L-1 R a$ en articulaciones reumatoideas reduce la enfermedad en modelos animales ${ }^{87}$ y en pacientes se ha mostrado que esta técnica permite la expresión intraarticular del gen $I L-1 R a$ de una manera segura ${ }^{88,89}$. Los condrocitos y las MSC resultan dianas preferentes para inductores de condrogénesis. Así, en modelos animales, el trasplante in vivo en lesiones condrales de MSC transfectadas con BMP-2 de ADNc aporta una mejor reparación, con una elevada producción de proteoglucanos y colágeno tipo $\mathrm{II}^{90}$. 


\section{Bibliografía}

1. Shapiro F, Koide S, Glimcher MJ. Cell origin and differentiation in the repair of fullthickness defects of articular cartilage. J Bone Joint Surg Am. 1993;75:532-53.

2. Friedman MJ, Berasi CC, Fox JM, Del Pizzo W, Snyder SJ, Ferkel RD. Preliminary results with abrasion arthroplasty in the osteoarthritic knee. Clin Orthop. 1984;182:200-5.

3. Muller B, Kohn D. Indication for and performance of articular cartilage drilling using the Pridie method. Orthopade. 1999;28:4-10.

4. Ficat RP, Ficat C, Gedeon P, Toussaint JB. Spongialization: a new treatment for diseased patellae. Clin Orthop. 1979;144:74-83.

5. Steadman J, Rodkey W, Briggs K, Rodrigo J. The microfracture technic in the management of complete cartilage defects in the knee joint. Orthopade. 1999;28:26-32.

6. Metsaranta M, Kujala UM, Pelliniemi L, Osterman H, Aho H, Vuorio E. Evidence for insufficient chondrocytic differentiation during repair of full-thickness defects of articular cartilage. Matrix Biol. 1996;15:39-47.

7. Menche DS, Frenkel SR, Blair B, Watnik NF, Toolan BC, Yaghoubian RS, et al. A comparison of abrasion burr arthroplasty and subchondral drilling in the treatment of fullthickness cartilage lesions in the rabbit. Arthroscopy. 1996;12:280-6.

8. Altman RD, Kates J, Chun LE, Dean DD, Eyre D. Preliminary observations of chondral abrasion in a canine model. Ann Rheum Dis. 1992;51:1056-62.

9. Knutsen G, Engebretsen L, Ludvigsen TC, Drogset JO, Grontvedt T, Solheim E, et al. Autologous chondrocyte implantation compared with microfracture in the knee. A randomized trial. J Bone Joint Surg Am. 2004;86:455-64.

10. Kreuz PC, Erggelet C, Steinwachs MR, Krause SJ, Lahm A, Niemeyer P, et al. Is microfracture of chondral defects in the knee associated with different results in patients aged 40 years or younger? Arthroscopy. 2006;22:1180-6.

11. Kreuz PC, Steinwachs MR, Erggelet C, Krause SJ, Konrad G, Uhl M, et al. Results after microfracture of full-thickness chondral defects in different compartments in the knee. Osteoarthritis Cartilage. 2006;14:1119-25.

12. Steadman JR, Briggs KK, Rodrigo JJ, Kocher MS, Gill TJ, Rodkey WG. Outcomes of microfracture for traumatic chondral defects of the knee: average 11-year follow-up. Arthroscopy. 2003;19:477-84.

13. O'Driscoll SW, Saris DB, Ito Y, Fitzimmons JS. The chondrogenic potential of periosteum decreases with age. J Orthop Res. 2001;19:95-103.

14. Duynstee ML, Verwoerd-Verhoef HL, Verwoerd CD, Van Osch GJ. The dual role of perichondrium in cartilage wound healing. Plast Reconstr Surg. 2002;110:1073-9.

15. Dounchis JS, Bae WC, Chen AC, Sah RL, Coutts RD, Amiel D. Cartilage repair with autogenic perichondrium cell and polylactic acid grafts. Clin Orthop Relat Res. 2000;(377):248-64.

16. Trzeciak T, Kruczynski J, Jaroszewski J, Lubiatowski P. Evaluation of cartilage reconstruction by means of autologous chondrocyte versus periosteal graft transplantation: an animal study. Transplant Proc. 2006;38:305-11.

17. Bouwmeester PS, Kuijer R, Homminga GN, Bulstra SK, Geesink RG. A retrospective analysis of two independent prospective cartilage repair studies: autogenous perichondrial grafting versus subchondral drilling 10 years post-surgery. J Orthop Res. 2002;20:267-73.

18. Van Susante JL, Wymenga AB, Buma P. Potential healing benefit of an osteoperiosteal bone plug from the proximal tibia on a mosaicplasty donor-site defect in the knee. An experimental study in the goat. Arch Orthop Trauma Surg. 2003;123:466-70.

19. Jung M, Gotterbarm T, Gruettgen A, Vilei SB, Breusch S, Richter W. Molecular characterization of spontaneous and growth-factor-augmented chondrogenesis in periosteum-bone tissue transferred into a joint. Histochem Cell Biol. 2005;123:447-56.

20. Zarnett R, Salter RB. Periosteal neochondrogenesis for biologically resurfacing joints: its cellular origin. Can J Surg. 1989;32:171-4.

21. Korkala OL, Kuokkanen HO. Autoarthroplasty of knee cartilage defects by osteoperiosteal grafts. Arch Orthop Trauma Surg. 1995;114:253-6.

22. Bartha L, Vajda A, Duska Z, Rahmeh H, Hangody L. Autologous osteochondral mosaicplasty grafting. J Orthop Sports Phys Ther. 2006;36:739-50.

23. Chow JC, Hantes ME, Houle JB, Zalavras CG. Arthroscopic autogenous osteochondral transplantation for treating knee cartilage defects: a 2- to 5-year follow-up study. Arthroscopy. 2004;20:681-90.

24. Hangody L, Fules P. Autologous osteochondral mosaicplasty for the treatment of fullthickness defects of weight-bearing joints: ten years of experimental and clinical experience. J Bone Joint Surg Am. 2003;85 Suppl 2:25-32.

25. Nakagawa Y, Suzuki T, Kuroki H, Kobayashi M, Okamoto Y, Nakamura T. The effect of surface incongruity of grafted plugs in osteochondral grafting: a report of five cases. Knee Surg Sports Traumatol Arthrosc. 2007 [en prensa]. 
26. McCulloch PC, Kang RW, Sobhy MH, Hayden JK, Cole BJ. Prospective evaluation of prolonged fresh osteochondral allograft transplantation of the femoral condyle: Minimum 2-year follow-up. Am J Sports Med. 2007;35:411-20.

27. Gross AE, Shasha N, Aubin P. Long-term followup of the use of fresh osteochondral allografts for posttraumatic knee defects. Clin Orthop Relat Res. 2005;(435):79-87.

28. Brittberg M, Lindahl A, Nilsson A, Ohlsson C, Isaksson O, Peterson L. Treatment of deep cartilage defects in the knee with autologous chondrocyte transplantation. N Engl J Med. 1994;331:889-95.

29. Richardson JB, Caterson B, Evans EH, Ashton BA, Roberts S. Repair of human articular cartilage after implantation of autologous chondrocytes. J Bone Joint Surg Br. 1999;81:1064-8.

30. Peterson L, Minas T, Brittberg M, Nilsson A, Sjogren-Jansson E, Lindahl A. Two- to 9 year outcome after autologous chondrocyte transplantation of the knee. Clin Orthop. 2000;374:212-34.

31. Roberts S, Hollander AP, Caterson B, Menage J, Richardson JB. Matrix turnover in human cartilage repair tissue in autologous chondrocyte implantation. Arthritis Rheum. 2001;44:2586-98.

32. Peterson L, Brittberg M, Kiviranta I, Akerlund EL, Lindahl A. Autologous chondrocyte transplantation. Biomechanics and long-term durability. Am J Sports Med. 2002;30:2-12.

33. Dell'Accio F, De Bari C, Luyten FP. Molecular markers predictive of the capacity of expanded human articular chondrocytes to form stable cartilage in vivo. Arthritis Rheum. 2001;44:1608-19.

34. Menche DS, Vangsness CT Jr, Pitman M, Gross AE, Peterson L. The treatment of isolated articular cartilage lesions in the young individual. Instr Course Lect. 1998;47:505-15.

35. O'Driscoll SW, Fitzsimmons JS. The role of periosteum in cartilage repair. Clin Orthop. 2001;391:S190-207.

36. Tins BJ, McCall IW, Takahashi T, Cassar-Pullicino V, Roberts S, Ashton B, et al. Autologous chondrocyte implantation in knee joint: MR imaging and histologic features at 1-year follow-up. Radiology. 2005;234:501-8.

37. Briggs TW, Mahroof S, David LA, Flannelly J, Pringle J, Bayliss M. Histological evaluation of chondral defects after autologous chondrocyte implantation of the knee. $\mathrm{J}$ Bone Joint Surg Br. 2003;85:1077-83.

38. Nah HD, Swoboda B, Birk DE, Kirsch T. Type IIA procollagen: expression in developing chicken limb cartilage and human osteoarthritic articular cartilage. Dev Dyn. 2001;220:307-22.

39. Bentley G, Biant LC, Carrington RW, Akmal M, Goldberg A, Williams AM, et al. A prospective, randomised comparison of autologous chondrocyte implantation versus mosaicplasty for osteochondral defects in the knee. J Bone Joint Surg Br. 2003;85:223-30.

40. Minas T, Peterson L. Chondrocyte transplantation. Op Tech Orthop. 1997;7:323-33.

41. Haddo O, Mahroof S, Higgs D, David L, Pringle J, Bayliss M, et al. The use of chondrogide membrane in autologous chondrocyte implantation. Knee. 2004;11:51-5.

42. Krishnan SP, Skinner JA, Carrington RW, Flanagan AM, Briggs TW, Bentley G. Collagen-covered autologous chondrocyte implantation for osteochondritis dissecans of the knee: two- to seven-year results. J Bone Joint Surg Br. 2006;88:203-5.

43. Robertson WB, Fick D, Wood DJ, Linklater JM, Zheng MH, Ackland TR. MRI and clinical evaluation of collagen-covered autologous chondrocyte implantation (CACI) at two years. Knee. 2007;14:117-27.

44. Gooding CR, Bartlett W, Bentley G, Skinner JA, Carrington R, Flanagan A. A prospective, randomised study comparing two techniques of autologous chondrocyte implantation for osteochondral defects in the knee: Periosteum covered versus type I/III collagen covered. Knee. 2006;13:203-10.

45. Wakitani S, Kimura T, Hirooka A, Ochi T, Yoneda M, Yasui N, et al. Repair of rabbit articular surfaces with allograft chondrocytes embedded in collagen gel. J Bone Joint Surg Br. 1989;71:74-80.

46. Rahfoth B, Weisser J, Sternkopf F, Aigner T, Von der Mark K, Brauer R. Transplantation of allograft chondrocytes embedded in agarose gel into cartilage defects of rabbits. Osteoarthritis Cartilage. 1998;6:50-65.

47. Schreiber RE, Ilten-Kirby BM, Dunkelman NS, Symons KT, Rekettye LM, Willoughby J, et al. Repair of osteochondral defects with allogeneic tissue engineered cartilage implants. Clin Orthop. 1999;367S:382-95.

48. Fuentes-Boquete I, López-Armada MJ, Maneiro E, Fernández-Sueiro JL, Caramés B, Galdo F, et al. Pig chondrocytes xenoimplants for human chondral defects repair: an in vitro model. Wound Repair Regen. 2004; 12:444-52.

49. Ramallal M, Maneiro E, López E, Fuentes-Boquete I, López-Armada MJ, FernándezSueiro JL, et al. Xeno-implant of chondrocytes to treat localized articular cartilage defects: an animal model, pig to rabbit. Wound Repair Regen. 2004;12:337-45. 
50. Rendal-Vázquez ME, Maneiro-Pampín E, Rodríguez-Cabarcos M, Fernández-Mallo O, López de Ullibarri I, Andión-Núñez C, et al. Effect of cryopreservation on human articular chondrocyte viability, proliferation, and collagen expression. Cryobiology. 2001;42:2-10.

51. Caplan AL. Mesenchymal stem cells. J Orthop Res. 1991;9:641-50.

52. Yoo JU, Barthel TS, Nishimura K, Solchaga L, Caplan AI, Goldberg VM, et al. The chondrogenic potential of human bone-marrow-derived mesenchymal progenitor cells. J Bone Joint Surg Am. 1998;80:1745-57.

53. Nakahara H, Bruder SP, Haynesworth SE, Holecek JJ, Baber MA, Goldberg VM, et al. Bone and cartilage formation in diffusion chambers by subcultured cells derived from the periosteum. Bone. 1990;11:181-8.

54. Dounchis JS, Goomer RS, Harwood FL, Khatod M, Coutts RD, Amiel D. Chondrogenic phenotype of perichondrium-derived chondroprogenitor cells is influenced by transforming growth factor-beta 1. J Orthop Res. 1997;15:803-7.

55. De Bari C, Dell'Accio F, Tylzanowski P, Luyten FP. Multipotent mesenchymal stem cells from adult human synovial membrane. Arthritis Rheum. 2001;44:1928-42.

56. Young HE, Steele TA, Bray RA, Hudson J, Floyd JA, Hawkins K, et al. Human reserve pluripotent mesenchymal stem cells are present in the connective tissues of skeletal muscle and dermis derived from fetal, adult, and geriatric donors. Anat Rec. 2001;264:5162.

57. Zuk PA, Zhu M, Mizuno H, Huang J, Futrell JW, Katz AJ, et al. Multilineage cells from human adipose tissue: implications for cell-based therapies. Tissue Engineering. 2001;7:211-28.

58. Mareschi K, Biasin E, Piacibello W, Aglietta M, Madon E, Fagioli F. Isolation of human mesenchymal stem cells: bone marrow versus umbilical cord blood. Haematologica. 2001;86:1099-100.

59. Kuznetsov SA, Mankani MH, Gronthos S, Satomura K, Bianco P, Robey PG. Circulating skeletal stem cells. J Cell Biol. 2001;153:1133-40.

60. Zvaifler NJ, Marinova-Mutafchieva L, Adams G, Edwards CJ, Moss J, Burger JA, et al. Mesenchymal precursor cells in the blood of normal individuals. Arthritis Res. 2000;2:477-88.

61. Alviano F, Fossati V, Marchionni C, Arpinati M, Bonsi L, Franchina M, et al. Term amniotic membrane is a high troughput source for multipotent mesenchymal stem cells with ability to differentate into endotheliar cells in vitro. BMC Developmental Biolology. 2007;7:11.

62. Alsalameh S, Amin R, Gemba T, Lotz M. Identification of mesenchymal progenitor cells in normal and osteoarthritic human articular cartilage. Arthritis Rheum. 2004;50:1522-32.

63. McGuckin CP, Forraz N, Baradez MO, Navran S, Zhao J, Urban R, et al. Production of stem cells with embryonic characteristics from human umbilical cord blood. Cell Prolif. 2005;38:245-55.

64. Prockop DJ. Marrow stromal cells as stem cells for non-hematopoietic tissues. Science. 1997;276:71-4.

65. Pittenger MF, Mackay AM, Beck SC, Jaiswal RK, Douglas R, Mosca JD, et al. Multilineage potential of adult human mesenchymal stem cells. Science. 1999;284:143-7.

66. Banfi A, Muraglia A, Dozin B, Mastrogiacomo M, Cancedda R, Quarto R. Proliferation kinetics and differentiation potential of ex vivo expanded human bone marrow stromal cells: Implications for their use in cell therapy. Exp Hematol. 2000;28:707-15.

67. Bonab MM, Alimoghaddam K, Talebian F, Ghaffari SH, Ghavamzadeh A, Nikbin B. Aging of mesenchymal stem cell in vitro. BMC Cell Biol. 2006;7:14-20.

68. Izadpanah R, Trygg C, Patel B, Kriedt C, Dufour J, Gimble JM, et al. Biologic properties of mesenchymal stem cells derived from bone marrow and adipose tissue. J Cell Biochem. 2006;99:1285-97.

69. Abdallah BM, Haack-Sorensen M, Burns JS, Elsnab B, Jakob F, Hokland P, et al. Maintenance of differentiation potential of human bone marrow mesenchymal stem cells immortalized by human telomerase reverse transcriptase gene despite [corrected] extensive proliferation. Biochem Biophys Res Commun. 2005;326:527-38.

70. Zimmermann S, Voss M, Kaiser S, Kapp U, Waller CF, Martens UM. Lack of telomerase activity in human mesenchymal stem cells. Leukemia. 2003;17:1146-9.

71. Parsch D, Fellenberg J, Brummendorf TH, Eschlbeck AM, Richter W. Telomere length and telomerase activity during expansion and differentiation of human mesenchymal stem cells and chondrocytes. J Mol Med. 2004;82:49-55.

72. Yanada S, Ochi M, Kojima K, Sharman P, Yasunaga Y, Hiyama E. Possibility of selection of chondrogenic progenitor cells by telomere length in FGF-2-expanded mesenchymal stromal cells. Cell Prolif. 2006;39:575-84.

73. Stenderup K, Justesen J, Clausen C, Kassem M. Aging is associated with decreased maximal life span and accelerated senescence of bone marrow stromal cells. Bone. 2003;33:919-26. 
74. Muraglia A, Cancedda R, Quarto R. Clonal mesenchymal progenitors from human bone marrow differentiate in vitro according to a hierarchical model. J Cell Sci. 2000;113:1161-6.

75. Djouad F, Bony C, Häupl T, Uzé G, Lahloy N, Louis-Plence P, et al. Transcriptional profiles discriminate bone marrow-derived and synovium-derived mesenchymal cells. Arthritis Res Ther. 2005;7:1304-15.

76. Sakaguchi Y, Sekiya I, Yagishita K, Muneta T. Comparison of human stem cells derived from various mesenchymal tissues. Arthritis Rheum. 2005;52:2521-9.

77. Im GI, Kim DY, Shin JH, Hyun CW, Cho WH. Repair of cartilage defect in the rabbit with cultured mesenchymal stem cells from bone marrow. J Bone Joint Surg $\mathrm{Br}$. 2001;83:289-94.

78. Murphy JM, Fink DJ, Hunziker EB, Barry FP. Stem cell therapy in a caprine model of osteoarthritis. Arthritis Rheum. 2003;48:3464-74.

79. Nishimori M, Deie M, Kanaya A, Exham H, Adachi N, Ochi M. Repair of chronic osteochondral defects in the rat. A bone marrow-stimulating procedure enhanced by cultured allogenic bone marrow mesenchymal stromal cells. J Bone Joint Surg Br. 2006;88:1236-44.

80. Agung M, Ochi M, Yanada S, Adachi N, Izuta Y, Yamasaki T, et al. Mobilization of bone marrow-derived mesenchymal stem cells into the injured tissues after intraarticular injection and their contribution to tissue regeneration. Knee Surg Sports Traumatol Arthrosc. 2006;14:1307-14.

81. Wakitani S, Imoto K, Yamamoto T, Saito M, Murata N, Yoneda M. Human autologous culture expanded bone marrow mesenchymal cell transplantation for repair of cartilage defects in osteoarthritic knees. Osteoarthritis Cartilage. 2002;10:199-206.

82. De Bari C, Dell'Accio F, Luyten FP. Failure of in vitro-differentiated mesenchymal stem cells from the synovial membrane to form ectopic stable cartilage in vivo. Arthritis Rheum. 2004;50:142-50.

83. Pelttari K, Winter A, Steck E, Goetzke K, Hennig T, Ochs BG, et al. Premature induction of hypertrophy during in vitro chondrogenesis of human mesenchymal stem cells correlates with calcification and vascular invasion after ectopic transplantation in SCID mice. Arthritis Rheum. 2006;54:3254-66.

84. Trippel SB, Ghivizzani SC, Nixon AJ. Gene-based approaches for the repair of articular cartilage. Gene Ther. 2004;11:351-9.

85. Gelse K, Von der Mark K, Schneider H. Cartilage regeneration by gene therapy. Curr Gene Ther. 2003;3:305-17.

86. Palmer G, Pascher A, Gouze E, Gouze JN, Betz O, Spector M, et al. Development of gene-based therapies for cartilage repair. Crit Rev Eukaryot Gene Expr. 2002;12:259-73.

87. Gouze E, Pawliuk R, Gouze JN, Pilapil C, Fleet C, Palmer GD, et al. Lentiviral-mediated gene delivery to synovium: potent intra-articular expression with amplification by inflammation. Mol Ther. 2003;7:460-6.

88. Evans CH, Robbins PD, Ghivizzani SC, Herndon JH, Wasko MC, Tomaino M, et al. Transfer and intra-articular expression of the IL-1Ra cDNA in human rheumatoid joints. Arthritis Res. 2001;3 Suppl 1:P33.

89. Evans CH, Robbins PD, Ghivizzani SC, Wasko MC, Tomaino MM, Kang R, et al. Gene transfer to human joints: progress toward a gene therapy of arthritis. Proc Natl Acad Sci U S A. 2005;102:8698-703.

90. Park J, Gelse K, Frank S, Von der Mark K, Aigner T, Schneider H. Transgene-activated mesenchymal cells for articular cartilage repair: a comparison of primary bone marrow-, perichondrium/periosteum- and fat-derived cells. J Gene Med. 2006;8:112-25. 